\title{
ASSESSING THE SERVICES QUALITY: EXPECTATIONS AND PERCEPTIONS OF PATIENTS RECEIVING PHYSIOTHERAPY SERVICES AT TEACHING HOSPITALS IN LAHORE, PAKISTAN
}

\author{
Maimoona Akhlaq Ahmed', Umair Ahmed', \\ Neelofar Rizwan', Sana Tauqeer ${ }^{1 \otimes}$, Hassan Javed ${ }^{1,2}$
}

\section{ABSTRACT}

OBJECTIVE: To assess the quality of physiotherapy services and patients' satisfaction based on Service Quality (SERVQUAL) at teaching hospitals in Lahore, Pakistan.

METHODS: This observational cross-sectional study was conducted from October 2018 to January 2019, on outpatients in teaching hospitals of Lahore, Pakistan. Patients aging from 19-60 years attending the outpatients of physical therapy departments of University of Lahore Teaching Hospital, WAPDA Hospital, Mayo Hospital and Pakistan Society of Rehabilitation of the Disabled were included in study. Patients refused to participate and those having compromised cognitive abilities were excluded from study. After taking informed consent, patients were asked to fill in the standardized SERVQUAL questionnaire before and after their physiotherapy session. Statistical analysis was carried out by using SPSS version 21 .

RESULTS: Out of 7 I patients $36(50.7 \%)$ were males and 35 (49.3\%) were females. Among 7 I patients; 43 (60.6\%) patients were satisfied and 28 (39.4\%) were dissatisfied, based on their expectations prior to receiving physiotherapy services The satisfaction level of patients, based on their experience of current physiotherapy session showed that $65 / 71$ ( $91.5 \%)$ patients were satisfied by the physiotherapy services provided to them whereas $6(8.4 \%)$ were dissatisfied $(p<0.00 \mathrm{I})$. The results showed that there was an inverse relation between patients' expectations and perceptions regarding Tangibles $(r=-0.248)$; Reliability $(r=-0.448)$; Responsiveness $(r=-0.298)$; Assurance $(r=-0.305)$ and Empathy $(r=-0.356)$.

CONCLUSION: There was an inverse relationship between perceptions and expectations. Patients were found to be more satisfied after experiencing physiotherapy services rather than before.

KEY WORDS: Patient Satisfaction (MeSH); SERVQUAL (Non-MeSH); Quality of Healthcare (MeSH); Quality Assurance Health Care (MeSH); Reliability (Non$\mathrm{MeSH}$ ); Tangibles (Non-MeSH); Responsiveness (Non-MeSH).

THIS ARTICLE MAY BE CITED AS: Ahmed MA, Ahmed U, Rizwan N, Tauqeer S, Javed $H$. Assessing the services quality: expectations and perceptions of patients receiving physiotherapy services at teaching hospitals in Lahore, Pakistan. Khyber Med Univ J 2019;12(2):|43-8. DOI: 10.35845/kmuj.2020.19445.

\section{INTRODUCTION}

$\mathrm{H}$ ealthcare provision is the basic human right of all people and it is the government responsibility to provide and improve the quality of health services in hospitals at reasonable cost.' In Pakistan, health-care services are provided by public and private hospitals across the country. Quality service is the extent to which healthcare designed for persons and populations enhance the chances of preferred health result. ${ }^{2}$ Quality is regarded as one of the key indexes in health and therapeutic services which involve three things that
I. University Institute of Physical Therapy, The University of Lahore, Defense Road Campus, Lahore, Pakistan.

2. Physiotherapist at the Pakistan Society for the Rehabilitation of the Disabled, Lahore, Pakistan. Email区: sanakhan2333444@gmail.com Contact \# : +92-324-4294807

$\begin{array}{ll}\text { Date Submitted: } & \text { July 04, 2019 } \\ \text { Date Revised: } & \text { April 02, 2020 } \\ \text { Date Accepted: } & \text { April 08, 2020 }\end{array}$

are the customer, technical, as well as service qualities. To begin with, customer quality is a set of abilities that are required by the care receiver to efficiently be utilized in healthcare procedure and vital decisions. Secondly, technical quality is the experimental feature of health care, which is reflected through healthcare providers, care processes, and outcomes. Lastly, service quality refers to unsanitary and harmful aspects, therefore, it reflects the association between the client and the giver of therapeutic processes. ${ }^{3}$ However, it is recommended that six aspects span the majority of the quality conception. These are effectiveness, competence, optimality, satisfactoriness, legitimacy, and impartiality. ${ }^{4}$ Once these are thought of individually or in different combinations, they shape the description of quality along with providing the extent of quality as soon as they are calculated by some means. $^{5}$

Service quality is the main dominant weapon of nearly all care organizations. Moreover, service quality makes way for giving health-associated requirements with minimum cost. ${ }^{6}$ Therefore, patients do not interfere with this observable detail, relatively, they only obtain the functional quality of services. ${ }^{7}$ Another significant feature is the execution of doctor-patient bond by regarding the patients beliefs and ethics as well as treating them with respect. ${ }^{8}$ The patient satisfaction can be described as fulfilling the patient's needs.' Patient's expectations are influenced by essentials such as past experience, word of mouth, healthcare givers status, mass media, adjoining factors, the requests and distinctiveness of the service consumer. ${ }^{10}$ As reported 
TABLE I: FREQUENCY DISTRIBUTION ACCORDING TO EXPECTATIONS

\begin{tabular}{|c|c|c|c|c|c|}
\hline Questions & $\begin{array}{l}\text { Strongly } \\
\text { Disagree }\end{array}$ & Disagree & Neutral & Agree & $\begin{array}{l}\text { Strongly } \\
\text { Agree }\end{array}$ \\
\hline Physiotherapy department has modern-looking equipment & $2(2.8)$ & $\mathrm{I}(\mathrm{I} .4 \%)$ & $8(11.3 \%)$ & $35(49.3 \%)$ & $25(35.2 \%)$ \\
\hline The physical facilities at physiotherapy departments are visually appealing & -- & $8(11.3 \%)$ & $\mathrm{I}(\mathrm{I} .4 \%)$ & $35(49.3 \%)$ & $27(38.0 \%)$ \\
\hline Personnel at physiotherapy departments are neat in appearance & $2(2.8 \%)$ & $7(9.9 \%)$ & -- & $37(52.1 \%)$ & $25(35.2 \%)$ \\
\hline $\begin{array}{l}\text { Materials associated with service (such as pamphlets or statements) } \\
\text { are visually appealing at the physiotherapy departments }\end{array}$ & $2(2.8 \%)$ & $7(9.9 \%)$ & $8(11.3 \%)$ & $3 I(43.7 \%)$ & $23(32.4 \%)$ \\
\hline $\begin{array}{l}\text { When physiotherapy department promises to do something by a certain } \\
\text { time it does so }\end{array}$ & - & $7(9.9 \%)$ & $4(5.6 \%)$ & $45(63.4 \%)$ & $15(21.1 \%)$ \\
\hline $\begin{array}{l}\text { When a patient has a problem, physiotherapy department shows a } \\
\text { sincere interest in solving it }\end{array}$ & $4(5.6 \%)$ & $4(5.6 \%)$ & $\mathrm{I}(\mathrm{I} .4 \%)$ & $40(56.3 \%)$ & $22(31.0 \%)$ \\
\hline Physiotherapy departments gets things right the first time & $4(5.6 \%)$ & $2(2.8 \%)$ & $\mathrm{I}(\mathrm{I} .4 \%)$ & $45(63.4 \%)$ & $19(26.8 \%)$ \\
\hline $\begin{array}{l}\text { Physiotherapy department provides their services at the time they } \\
\text { promise to do so }\end{array}$ & $4(5.6 \%)$ & $5(7.0 \%)$ & -- & $36(50.7 \%)$ & $26(36.6 \%)$ \\
\hline Physiotherapy department insists on error-free records & $4(5.6 \%)$ & $4(5.6 \%)$ & $2(2.8 \%)$ & $4 I(57.7 \%)$ & $20(28.2 \%)$ \\
\hline Physiotherapist tells patients exactly when services will be performed & $4(5.6 \%)$ & $4(5.6 \%)$ & -- & $37(52.1 \%)$ & $26(36.6 \%)$ \\
\hline Physiotherapist gives prompt service to patients & $2(2.8 \%)$ & $10(14.1 \%)$ & $\mathrm{I}(\mathrm{I} .4 \%)$ & $31(43.7 \%)$ & $27(38.0 \%$ \\
\hline Physiotherapist is always willing to help patients & $2(2.8 \%)$ & $4(5.6 \%)$ & $3(4.2 \%)$ & $28(39.4 \%)$ & $34(47.9 \%)$ \\
\hline Physiotherapists are never be too busy to respond to patients' requests & $2(2.8 \%)$ & $10(14.1 \%)$ & $\mathrm{I}(\mathrm{I} .4 \%)$ & $32(45.1 \%)$ & $26(36.6 \%)$ \\
\hline The behavior of physiotherapists instilled confidence in patients & $2(2.8 \%)$ & $5(7.0 \%)$ & -- & $25(35.2 \%)$ & $39(54.9 \%)$ \\
\hline Other patients feel safe in their dealings with the physiotherapy department & $2(2.8)$ & $3(4.2 \%)$ & $3(4.2 \%)$ & $25(35.2 \%)$ & $38(53.5 \%)$ \\
\hline Physiotherapists are consistently courteous with the patients & $2(2.8 \%)$ & $4(5.6 \%)$ & -- & $27(38.0 \%)$ & $38(53.5 \%)$ \\
\hline Physiotherapists have the knowledge to answer patients' questions & $4(5.6 \%)$ & $2(2.8 \%)$ & $3(4.2 \%)$ & $29(40.8 \%)$ & $33(46.5 \%)$ \\
\hline Physiotherapy department gives patients individual attention & $2(2.8 \%)$ & $4(5.6 \%)$ & -- & $27(38.0 \%)$ & $38(53.5 \%)$ \\
\hline Physiotherapy department has operating hours convenient to all their patients & --- & $9(12.7 \%)$ & -- & $25(35.2 \%)$ & $37(52.1 \%)$ \\
\hline Physiotherapy department has staff who give patients personal attention & -- & $7(9.9 \%)$ & -- & $35(49.3 \%)$ & $29(40.8 \%)$ \\
\hline Physiotherapy department has the patient's best interests at heart & $2(2.8 \%)$ & $10(14.1 \%)$ & -- & $30(42.3 \%)$ & $29(40.8 \%)$ \\
\hline Physiotherapist understands the specific needs of their patients & $2(2.8 \%)$ & $6(8.5 \%)$ & $2(2.8 \%)$ & $26(36.6 \%)$ & $35(49.3 \%)$ \\
\hline
\end{tabular}

in the earlier studies, one of the highly significant troubles in organizations is giving little notice to or disregarding the clients' requests and requirements."

Rehabilitation medicine and physiotherapy services are helpful in accelerating the therapeutic course and improvement in patents recovery. ${ }^{12}$ However, in our set up, limited studies are conducted on patients' satisfaction and quality of physiotherapy and rehabilitation services provided at local teaching hospital. We planned this study to assess the service quality of physiotherapy services at teaching hospitals in Lahore, Pakistan using the SERVQUAL scale, to assess and improve the satisfaction level of patients, to explore the link between satisfaction level of patients and socio demographic factors.

\section{METHODS}

This observational cross-sectional study was conducted from October 2018 to January 2019 . Sample size was calculated as 7I patients by using the estimation of single proportion method. Sample was collected using the nonprobability convenience sampling method. ${ }^{13}$ The study was conducted in various teaching hospitals of Lahore, Pakistan, including University of Lahore (UOL) Teaching Hospital, Water and Power Development Authority (WAPDA) Teaching Hospital, Mayo Hospital and The Pakistan Society for Rehabilitation of The Disabled (PSRD). The subjects included were all outpatients in physiotherapy departments at teaching hospitals, males and females, those aged between 19 to 60 years and those who filled the consent form. Excluded subjects were all those who failed to meet the inclusion criteria and those with compromised cognitive abilities. Our study was completed within four months following the approval of synopsis. The SERVQUAL (Service Quality) Questionnaire ${ }^{14}$ that had been used in this research was an orderly, standardized Survey. It constitutes of 22 questions along with the dimensions recognized in SERVQUAL (Service Quality) items are as follows:

a) Tangibles: Advanced modalities, physical services with neatness of staff and personnel

b) Reliability: Capability of performing the assured services reliably and precisely

c) Responsiveness: Enthusiasm in helping patients with providing timely services

d) Assurance: Information along with courteousness of personnel as well as their skill to instigate confidence plus assurance 
TABLE II: FREQUENCY DISTRIBUTION ACCORDING TO PERCEPTIONS

\begin{tabular}{|c|c|c|c|c|c|}
\hline Questions & $\begin{array}{l}\text { Strongly } \\
\text { Disagree }\end{array}$ & Disagree & Neutral & Agree & $\begin{array}{l}\text { Strongly } \\
\text { Agree }\end{array}$ \\
\hline Physiotherapy department has modern-looking equipment & $2(2.8)$ & $\mathrm{I}(\mathrm{I} .4 \%)$ & $8(I 1.3 \%)$ & $35(49.3 \%)$ & $25(35.2 \%)$ \\
\hline The physical facilities at physiotherapy departments are visually appealing & -- & $8(11.3 \%)$ & $\mathrm{I}(\mathrm{I} .4 \%)$ & $35(49.3 \%)$ & $27(38.0 \%)$ \\
\hline Personnel at physiotherapy departments are neat in appearance & $2(2.8 \%)$ & $7(9.9 \%)$ & -- & $37(52.1 \%)$ & $25(35.2 \%)$ \\
\hline $\begin{array}{l}\text { Materials associated with service (such as pamphlets or statements) } \\
\text { are visually appealing at the physiotherapy departments }\end{array}$ & $2(2.8 \%)$ & $7(9.9 \%)$ & $8(11.3 \%)$ & $31(43.7 \%)$ & $23(32.4 \%)$ \\
\hline $\begin{array}{l}\text { When physiotherapy department promises to do something by a certain } \\
\text { time it does so }\end{array}$ & - & $7(9.9 \%)$ & $4(5.6 \%)$ & $45(63.4 \%)$ & $15(21.1 \%)$ \\
\hline $\begin{array}{l}\text { When a patient has a problem, physiotherapy department shows a } \\
\text { sincere interest in solving it }\end{array}$ & $4(5.6 \%)$ & $4(5.6 \%)$ & $\mathrm{I}(\mathrm{I} .4 \%)$ & $40(56.3 \%)$ & $22(31.0 \%)$ \\
\hline Physiotherapy departments gets things right the first time & $4(5.6 \%)$ & $2(2.8 \%)$ & $\mathrm{I}(\mathrm{I} .4 \%)$ & $45(63.4 \%)$ & $19(26.8 \%)$ \\
\hline $\begin{array}{l}\text { Physiotherapy department provides their services at the time they } \\
\text { promise to do so }\end{array}$ & $4(5.6 \%)$ & $5(7.0 \%)$ & -- & $36(50.7 \%)$ & $26(36.6 \%)$ \\
\hline Physiotherapy department insists on error-free records & & & $2(2.8 \%)$ & $4 \mathrm{I}(57.7 \%)$ & $20(28.2 \%)$ \\
\hline Physiotherapist tells patients exactly when services will be performed & $4(5.6 \%)$ & $4(5.6 \%)$ & -- & $37(52.1 \%)$ & $26(36.6 \%)$ \\
\hline Physiotherapist gives prompt service to patients & $2(2.8 \%)$ & $10(14.1 \%)$ & $\mathrm{I}(\mathrm{I} .4 \%)$ & $31(43.7 \%)$ & $27(38.0 \%$ \\
\hline Physiotherapist is always willing to help patients & $2(2.8 \%)$ & $4(5.6 \%)$ & $3(4.2 \%)$ & $28(39.4 \%)$ & $34(47.9 \%)$ \\
\hline Physiotherapists are never be too busy to respond to patients' requests & $2(2.8 \%)$ & $10(14.1 \%)$ & $\mathrm{I}(\mathrm{I} .4 \%)$ & $32(45.1 \%)$ & $26(36.6 \%)$ \\
\hline The behavior of physiotherapists instilled confidence in patients & $2(2.8 \%)$ & $5(7.0 \%)$ & -- & $25(35.2 \%)$ & $39(54.9 \%)$ \\
\hline Other patients feel safe in their dealings with the physiotherapy department & $2(2.8)$ & $3(4.2 \%)$ & $3(4.2 \%)$ & $25(35.2 \%)$ & $38(53.5 \%)$ \\
\hline Physiotherapists are consistently courteous with the patients & $2(2.8 \%)$ & $4(5.6 \%)$ & -- & $27(38.0 \%)$ & $38(53.5 \%)$ \\
\hline Physiotherapists have the knowledge to answer patients' questions & $4(5.6 \%)$ & $2(2.8 \%)$ & $3(4.2 \%)$ & $29(40.8 \%)$ & $33(46.5 \%)$ \\
\hline Physiotherapy department gives patients individual attention & $2(2.8 \%)$ & $4(5.6 \%)$ & -- & $27(38.0 \%)$ & $38(53.5 \%)$ \\
\hline Physiotherapy department has operating hours convenient to all their patients & --- & $9(12.7 \%)$ & -- & $25(35.2 \%)$ & $37(52.1 \%)$ \\
\hline Physiotherapy department has staff who give patients personal attention & -- & $7(9.9 \%)$ & -- & $35(49.3 \%)$ & $29(40.8 \%)$ \\
\hline Physiotherapy department has the patient's best interests at heart & $2(2.8 \%)$ & $10(14.1 \%)$ & -- & $30(42.3 \%)$ & $29(40.8 \%)$ \\
\hline Physiotherapist understands the specific needs of their patients & $2(2.8 \%)$ & $6(8.5 \%)$ & $2(2.8 \%)$ & $26(36.6 \%)$ & $35(49.3 \%)$ \\
\hline
\end{tabular}

TABLE III: PAIRED SAMPLE T-TEST

\begin{tabular}{|l|c|c|c|c|}
\hline \multicolumn{1}{|c|}{ Dimensions } & Expectations & Perceptions & Correlation & p-value \\
\hline Tangibles & $12.90 \pm 1.78$ & $16.26 \pm 3.23$ & -0.248 & $<0.00 I^{*}$ \\
\hline Reliability & $14.84 \pm 3.63$ & $20.02 \pm 4.45$ & -0.448 & $<0.00 I^{*}$ \\
\hline Responsiveness & $12.28 \pm 2.23$ & $16.3 \mathrm{I} \pm 3.58$ & -0.298 & $<0.00 \mathrm{I}^{*}$ \\
\hline Assurance & $12.80 \pm 2.00$ & $\mathrm{I} 7.18 \pm 3.63$ & -0.305 & $<0.00 \mathrm{I}^{*}$ \\
\hline Empathy & $\mathrm{I} 4.34 \pm 2.42$ & $2 \mathrm{I} .07 \pm 4.26$ & -0.356 & $<0.00 \mathrm{I}^{*}$ \\
\hline
\end{tabular}

e) Empathy: Considerate, personalized concentration

The SERVQUAL (Service Quality) Instrument has been a chief method developed for the measurement of client satisfaction in every healthcare organization and calculation of the gap of work or services that fulfill the clients prospection via generating discrepancy between patients prospection and perception of the healthcare services experienced. ${ }^{15}$ Clients were encouraged to select their level of congruity or incongruity, by means of a
Five-Point Likert Scale, in which I denoted strong disagreement and 5 denoted strong agreement of the relevant query. The client or patient was classified as being satisfied if the score results in 3 and/or higher whereas, the client or patient was classified as being dissatisfied if the score results in lesser than 3. ${ }^{12}$ The SERVQUAL (Service Quality) Questionnaire constitutes of three parts. Section one constitutes of socio demographic information covering the aspects of age, gender, educational status, working status, number of visits, waiting time and address. In Section two, subjects were inquired regarding their prospects that consisted of 22 questions. Moreover, the third section also constituted of 22 questions relating to the patient's perceptions. To begin with, among the 22 questions in both the factors of expectations and perceptions, I to 4 were those under the dimension of tangibles; questions 5 to 9 lie under the dimension of reliability; questions 10 to I 3 fall under the dimension of responsiveness; questions 14 to 17 are categorized under the assurance dimension; lastly, questions 18 to 22 denote the dimensions of empathy. Throughout the sampling procedure, the section one and section two were handed to the patients while their registration was in process at the reception, whereas the section three was handed to patients as soon as the session of the treatment was concluded. Completely filled questionnaires were taken for samples. Question 18 fulfilled 
the purpose of measuring patients' perceptions based on experience concerning the satisfaction with physiotherapy services provided as a whole. The statistical analyses were performed using the Statistical Package for Social Science (SPSS) software version 21.0 and Microsoft Office Excel 2007. The Statistical value was regarded as noteworthy if $p$ value $<0.05 .^{10}$ The descriptive statistics were computed for all the variables and the sum of each dimension, namely, Tangibles, Reliability, Responsiveness, Assurance and Empathy was calculated for both, expectations as well as perceptions. The means of expectations and perceptions were then computed and their differences were correlated. The frequency distributions were generated for all variables, namely, gender, age, marital status, educational status, working status, number of visits, waiting time, and the ratings of all the 22 questions for each of expectations as well as perceptions. The service quality gap was then calculated by the arithmetical difference between expectations and perceptions and then correlated. The results were tabulated and the hypothesis was tested using the paired sample t-test. Association of SERVQUAL (Service Quality) with satisfaction level of patients' expectations as well as the satisfaction level of patients' perceptions was then generated based on scores.

The study did not involve invasive procedures, or personal identifying data. The study has been conducted under moral and ethical circumstances and no principles or laws have been violated. The females involved in this research were interviewed solely for the purpose of baseline study. All authors are legally involved in this study and no gift authorship has been granted. Written consent form was duly given and completely filled by the included subjects. Any incomplete questionnaires were wasted.

\section{RESULTS}

Out of 7 I patients $36(50.7 \%)$ were males and 35 (49.3\%) were females. Among 7I patients' expectations, 43 $(60.6 \%)$ patients were satisfied based on their expectations and 28 (39.4\%) were dissatisfied based on their expectations prior to receiving physiotherapy services (Question 18: Physiotherapy department will give patients individual attention) (Table I). The satisfaction level of patients based on their experiences shows that 65 ( $91.5 \%)$ patients were satisfied by the physiotherapy services provided to them whereas six $(8.4 \%)$ were dissatisfied (Question 18: Physiotherapy department gives patients individual attention) (Table II). *p-value significant at 0.05 , paired sample $t$ test. The results showed that there was an inverse relation between patients' expectations and perceptions $(p<0.00 \mathrm{I})$. Furthermore, the results also revealed an inverse relation between patients' expectations and perceptions regarding Tangibles $(r=-$ $0.248)$; Reliability ( $r=-0.448)$; Responsiveness ( $r=-0.298)$; Assurance $(r=-0.305)$ and Empathy $(r=-0.356)$. (Table III).

\section{DISCUSSION}

The teaching hospitals in Lahore, Pakistan are trying their level best in providing the best healthcare physiotherapy services to their patients and are making their best efforts in coping with the provision of modern technological equipment in their physical therapy departments in both public and private sectors.

An earlier study conducted in Kelang Valley, Malaysia showed the satisfaction level of patients based on their expectations to be $95.2 \%$ and their satisfaction level based on perceptions to be $99.7 \% .^{12}$ Whereas, this study has shown that about $60.6 \%$ patients were satisfied with the physiotherapy services provided to them with respect to their expectations, whereas, with respect to their experience or perceptions, $91.5 \%$ patients were satisfied with the physiotherapy services provided to them at teaching hospitals in Lahore, Pakistan. The difference in the satisfaction level among patients could possibly be due to the developing stage of our nation and the lack of modernized modalities.

Regarding gender groups, there was a significant association with the level of patient satisfaction. Previous studies have shown that males were more satisfied as compared to females. ${ }^{16}$ This study resulted in female patients tending to be more satisfied than male patients with the physiotherapy services provided to them because males have greater expectations than females. Males were indeed found to be more concerned with the healthcare services than females. Gender related difference in satisfaction with physical therapy services might need further exploration.

The elderly population often rated the care offered to them with more positivity and higher motivation as compared to younger individuals. ${ }^{17}$ Whereas, the statistical investigation in this study displayed that the patient satisfaction at teaching hospitals in physiotherapy clinics is increased among individuals aged less than 40 years and more than 56 years as compared to those aged between 40 and 56 years. The patients aged between 40 and 56 years have portrayed higher anticipation and tend to become annoyed easily due to some environmental factors and so they have reduced tolerance.

Married patients showed higher satisfaction levels than bachelor patients. ${ }^{18}$ This has contradicted with this study as unmarried individuals were displayed to have a greater percentage of satisfaction as compared with the married patients. The unmarried individuals are more immature and take everything nonchalantly so they easily become satisfied with the healthcare services provided.

With respect to the educational class, result of this research displayed that patients having lower degree of educational category were discovered to have an increased satisfaction level comparative with patients having higher degree of educational class and was analogous with earlier studies regarding patient satisfaction. ${ }^{18}$ This can be described as patients having higher educational status will be having high expectations of received services comparative with patients having a lower educational status since they are further open to the elements of advanced knowledge, advanced informative technology as well as expansive reporting by up to date mass communicative media.

Amongst the categories of working status, the arithmetical examination has shown to have a significant connection between working status and the satisfaction level of patients through services provided at physiotherapy departments in teaching hospitals which is also shown in earlier researches. Those patients who were 
unemployed were discovered to have an increased level of satisfaction with respect to physiotherapy services offered as compared to those patients who were working. This can be described as employed patients will tend to have high financial expectations of healthcare services that they ought to receive comparative with non working patients, increasingly open to the elements of universal socialization surroundings as well as service level to different service provision centers. ${ }^{19}$ The working status has shown to have noteworthy relationship with the satisfaction level of patients in physiotherapy departments at teaching hospitals in Lahore, Pakistan.

Outcomes as of this study revealed that the amount of visits had a considerable connection with the satisfaction level of patients. Previous study showed that those patients who attended more than three times are more satisfied than the patients having attended thrice and fewer. Our study has shown similar results. This might probably be owed to diminished levels of respondents' tension caused by the speedy procedure of improvement of poor health that results when the patients visited the physiotherapy departments more than thrice, they became more contented than they were previously since they might have revealed or undergone more optimistic aspects followed by the amount of visits, assurance regarding their future health and possibly their willingness to go back to employment or professional opportunities.'

In terms of waiting time period, the result of this research contradicts outcomes from earlier study that the waiting time had no considerable relationship with satisfaction level of patients. Our study showed that patients who waited for less than 30 minutes had a higher satisfaction level as compared to those patients who had to wait for more than 30 minutes. ${ }^{19}$

Quality in expression of healthiness deliverance denoted the healthcare examinations and services that deal with to meeting the appropriate principles, entailing brilliance and assurance of the requirements of both delegations which were the healthcare receiver and service givers. ${ }^{20}$ SERVQUAL (Service Quality) has served the purpose of a diagnostic gadget where the interventional services 'Quality Gap' are acknowledged by healthcare receivers and also permits prioritizing through the five dimensions. ${ }^{21}$
Through the five dimensions of SERVQUAL (Service Quality), arithmetically or statistically noteworthy gap scores were discovered for Tangibles, Reliability, Responsiveness, Assurance and Empathy. ${ }^{22}$

The outcome of this study shows that the greatest satisfaction achieved among the patients was that related to reliability, specifically evolving around the punctuality of physiotherapists in beginning the treatment, and the greatest disappointment was shown in the dimension of tangibles, specifically relating to the appearance and neatness of the physiotherapy departments as well as of the personnel and the lack of modernized treatment equipment.

Quarter of the complaints were based on the behaviour of physiotherapists, in that the patients criticized on the lack of understanding of their condition and their requirements by the physiotherapists as well as on the lack of availability of physiotherapists at all times. This is because of the lack of enthusiasm to treat patients due to the pressurizing impact of our society and the lack of awareness about our profession in this society. However, the complementary suggestions shall motivate physiotherapists in Lahore and encourage them to emphasize more on setting up private clinics for patients who are unable to reach them during the teaching hospital hours, focus more on getting equipped with up-to-date modalities and maintain a neat and organized environment for every patient or client they deal with.

This study is limited to Lahore city of Pakistan. We only found the quality gap between expectations and perceptions of outpatients. The study was limited to close-ended answers; patients' detailed impressions were unable to be recorded for study.

Further study is required to be carried out using a larger population sample. More researches are required to be carried out highlighting the quality gap among patients obtaining physiotherapy at both, government and private sectors.

\section{CONCLUSION}

The discoveries of this study enlighten that the performance of the physiotherapists at teaching hospitals in meeting with the patient's expectations is on a moderate level. These findings highlight that focus needs to be more on improvement of the Tangibles (updating modalities and patients' personal hygiene) within the physiotherapy departments as well as professional Empathy of all therapists by maintaining a positive attitude towards patients and clients.

\section{REFERENCES}

I. Bauer JE, Duffy GL, Westcott R. The quality improvement handbook: ASQ Quality Press; 2006.

2. Nasim K, Janjua SY. Service quality perceptions and patients' satisfaction: a comparative case study of a public and a private sector hospital in Pakistan. Int J Qual Res 20 I4;8(3):44760.

3. Vadhana M. Assessment of patient satisfaction in an outpatient department of an autonomous hospital in Phnom Penh. Pacific University, Cambodia. 2012.

4. Lakatos P, Toth E, Cina Z, Lang Z, Psachoulia E, Intorcia M. Persistence \& compliance to treatment for osteoporosis in postmenopausal women in Hungary: a retrospective cohort study. Val Health 20।3; I6(7):A567-A8. DOI: 10.1016/j.jval.2013.08.1516.

5. Isik $O$, Tengilimoglu D, Akbolat M. Measuring health care quality with the SERVQUAL method: a comparison in public and private hospitals. Health Med 20I I;5(6): 192I-30.

6. Havasbeigi F, Yasbalaghisharahi B, Mohamadi E, Mohamadi A. Measuring the quality of services provided for outpatients in public hospitals in Ilam and Kermanshah cities based on the SERVQUAL instrument. J Ilam Univ Med Sci 20 I 3;2I (I):207-I.

7. Juma D, Manongi R. Users' perceptions of outpatient quality of care in Kilosa District Hospital in central Tanzania. Tanzan J Health Res 2009 Oct; II (4): 196-204. DOI: I0.43|4/thrb.v| li4.50176.

8. Col AC. Evaluation of service quality of hospital outpatient department services. Med J Armed Forces India 20II Jul;67(3):22I-4. DOI: 10.1016/S0377-1237(II)60045-2.

9. Beach MC, Sugarman J, Johnson RL, Arbelaez JJ, Duggan PS, Cooper LA. Do patients treated with dignity report higher satisfaction, adherence, 
and receipt of preventive care? Ann Fam Med Jul-Aug 2005;3(4):33I-8. DOI: 10.1370/afm.328.

10. Roslan M, Tahir A, Nasir A. Patient satisfaction in Public Hospitals. Ministry of Health Malaysia Medical Development Division Report: Kuala Lumpur. 2005.

I I. Hayati IN, Azimatun N, Rozita H, Ezat W, Rizal A. In-patient's satisfaction in the medical and surgical wards-A comparison between accreditted and non accreditated hospital in the state of Selangor. J Kesihatan Masyarakat 2010;16(I):60-8.

12. Nasaruddin Mahdzir M, Aniza I, Faridah A, Sulha A. Assessing the service quality of physiotherapy services: A cross sectional study at teaching hospitals in Klang Valley, Malaysia. Malays J Public Health Med 2013;13(2):27-37.

13. Marzban S, Najafi M, Etedal M, Moradi $S$, Rajaee R. The evaluation of outpatient quality services in physiotherapy in the teaching health centers of Shahid Beheshti University based on SERVQUAL tools. Eu J Biol Med Sci Res 20 I 5;3(3):46-53.

14. Lwanga SK, Lemeshow S, Organization WH. Sample size determination in health studies: a practical manual: World Health Organization; 1991.

15. Zeithaml VA, Berry LL, Parasuraman A. SERVQUAL: a multiple-item scale for measuring consumer perceptions of service quality. J Retail 1988;64(I): 12-40.

16. Yeşilada F, Direktouml E. Health care service quality: A comparison of public and private hospitals. Afr J Bus Manag 2010;4(6):962-7I.

17. Xiao J, Zhou X, Zhu W, Zhang B, Li J, $\mathrm{Xu} X$. The prevalence of tooth discolouration and the self satisfaction with tooth colour in a Chinese urban population. J Oral Rehabil 2007 May;34(5):35 I-60. DOI: I0. I I I //j. I365-2842.2007.01729.x.

18. Aniza I, Suhaila A. Clients satisfactions in ISO certified health clinic in Klinik Kesihatan Bandar Baru Bangi, Selangor and its associated factors. J
Kesihatan Masyarakat 201 I; I7(I): 1825.

19. Agyeman FKA. The perceptions and experiences of men's involvement in antenatal and postnatal care: a study of Greenhill community at Oyarifa in Ghana: University of Ghana; 2016.

20. Aniza I, Rizal M, Mardhiyyah M, Helmi I, Syamimi B, Tahar M. Caregivers' satisfaction of healthcare delivery at pediatric clinics of University Kebangsaan Malaysia Medical Centre in 2009. Med J Malaysia 20I I;66(2):84-8.

21. Arries EJ, Newman O. Outpatients' experiences of quality service delivery at a teaching hospital in Gauteng. Health SA Gesondheid (Online). 2008; I 3(I):4I-54.

22. Wisniewski M, Wisniewski $H$. Measuring service quality in a hospital colposcopy clinic. Int J Health Care Qual Assur Inc Leadersh Health Serv 2005; I8(2-3):217-28. DOI: I0.1 I08/ 09526860510594776 .

\section{AUTHORS' CONTRIBUTIONS}

Following authors have made substantial contributions to the manuscript as under:

MAA: Conception and study design, acquisition of data, drafting the manuscript, critical review, final approval of the version to be published.

UA, ST \& HJ: acquisition of data, drafting the manuscript, final approval of the version to be published.

NR: Analysis and interpretation of data, drafting the manuscript, critical review, final approval of the version to be published.

Authors agree to be accountable for all aspects of the work in ensuring that questions related to the accuracy or integrity of any part of the work are appropriately investigated and resolved.

CONFLICT OF INTEREST

Authors declared no conflict of interest GRANT SUPPORT AND FINANCIAL DISCLOSURE NIL

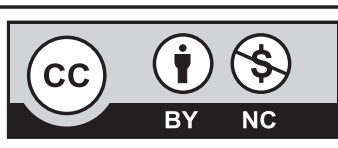

This is an Open Access article distributed under the terms of the Creative Commons Attribution-Non Commercial 2.0 Generic License.

KMUJ web address: www.kmuj.kmu.edu.pk

Email address: kmuj@kmu.edu.pk 